National Marine

Fisheries Service

NOAA
Fishery Bulletin

a established in 1881 a
Spencer F. Baird

First U.S. Commissione of Fisheries and founder of Fishery Bulletin
Abstract-The U.S. National Marine Fisheries Service has undertaken to measure the economic performance of fisheries that have implemented catch shares as a management strategy. Among the metrics used, change in productivity was identified as important, and considerable research has been conducted to construct metrics and to measure this change. We introduce the Bennet-Bowley (BB) indicator as another tool to measure change in productivity, show how to construct the indicator, and apply it to the northeast multispecies fishery, which adopted a catch share system in 2010. The BB indicator is then used to show the contribution of vessels entering, continuing within, and exiting the fishery to overall fleet productivity. Results showed that after catch share management, fleet productivity declined and that vessels continuing in the fishery as a group contributed the most to a decline in aggregate productivity. On a per-vessel basis, a core group of vessels continuing in the fishery and that were present throughout the study period showed a decline in productivity after catch share management was impletemented. These declines were caused by reduced outputs (i.e. catch) in relation to use of inputs (e.g. labor, fuel, materials) after catch shares were implemented.

Manuscript submitted 5 August 2016. Manuscript accepted 16 March 2017. Fish. Bull. 115:273-283 (2017)

Online publication date: 25 April 2017. doi: 10.7755/FB.115.3.1

The views and opinions expressed or implied in this article are those of the author (or authors) and do not necessarily reflect the position of the National Marine Fisheries Service, NOAA.

\title{
Measuring change in productivity of a fishery with the Bennet-Bowley indicator
}

John B. Walden (contact author) ${ }^{1}$

Rolf Färe ${ }^{2,3}$

Shawna Grosskopf ${ }^{4,5}$

Email address for contact author: john.walden@noaa.gov

1 Northeast Fisheries Science Center
National Marine Fisheries Service, NOAA
166 Water Street
Woods Hole, Massachusetts 02543
2 Department of Economics and
Department of Applied Economics
Oregon State University
Ballard Extension Hall
Corvallis, Oregon 97331
${ }^{3}$ Department of Agricultural and
Resource Economics
University of Maryland
College Park, Maryland 20742

\author{
4 Department of Economics \\ Oregon State University \\ Bexell Hall \\ Corvallis, Oregon 97331 \\ 5 Centre for Environmental and Resource \\ Economics (CERE) \\ Department of Economics \\ Umeå University \\ S-901 87, Umeå, Sweden
}

Management of commercial and recreational fisheries has long been a topic of interest in public policy circles. This interest is due to the common pool nature of the resource, and the human dimension of the various user groups that rely on the resource for food, income, and recreational opportunities. Policy choices for the management of the resource are typically multidimensional, and involve a variety of regulatory instruments to control catch. Because management decisions are usually tied to the status of fish stocks, governments typically monitor and assess changes in the fish biomass on a regular basis. However, there is often not an equivalent monitoring system to track changes in the socio-economic status and well-being of resource users who depend on the fishery for part, or all, of their livelihood.

Gradually, there has been a shift in terms of assessing changes which take place among marine fishery user groups, particularly after impor- tant management modifications have taken place. In the United States, this shift in appraisal has been partially due to further adoption of "rights based management" in fisheries, also known as "catch shares," which secures a certain share of the total allowable catch (TAC) from a fishery for an individual vessel owner, community or association. Although catch shares have existed in some form since 1990 in U.S. fisheries, recent interest in expanding catch shares to multiple fisheries has generated interest in creating a consistent set of socio-economic performance indicators for these fisheries (Clay et al., 2014; Murphy et al., 2015). Currently, the same effort has not taken place for recreational fisheries. Consequently, the focus in our study will be on commercial fishing vessels.

The interest in evaluating economic and social changes centered on fishing fleets and communities is a positive development. It recognizes 
that a more complete evaluation of management success includes changes that occur in the harvesting sector and how the people who depend on the resource for their livelihood are impacted by management choices. An initial set of indicators developed in the U.S. northeast region were broken into 5 broad groupings: financial viability, distributional outcomes (i.e. distibution of benefits and costs of a program among individuals, groups and communities), governance, stewardship, and well-being of fishermen and fishing communities (Clay et al., 2014). The choice of these categories was the result of a collaborative effort among economists and other social scientists in the northeast region.

Among the indicators of financial improvement, a change in productivity, hereafter "productivity change," has been the focus of a concerted effort within the U.S. National Marine Fisheries Service (Walden et al., 2012, 2015; Thunberg et al., 2015). Simply put, productivity change describes how the landings from fishing vessels, and the inputs (fuel, labor, materials) used to produce those landings change through time. This indicator is important because productivity change is directly tied to profit change. If, for example, prices for the fish landed are stable, and the inputs such as fuel used on a fishing trip do not change, profits can increase if vessels are able to produce more landings (outputs) for a given level of inputs.

Because fishing vessels typically land more than one species of fish and use several different inputs such as fuel, labor, and vessel capital to land fish, in order to measure productivity, both landings and inputs need to be aggregated into single values. Combining input and outputs into single values is typically done with aggregators, which are determined by either nonparametric or parametric programming methods, or by prices. In this article, we use prices to aggregate inputs and outputs. Once the landings produced (noted as ' $\mathrm{Y}$ ') and the inputs used (noted as ' $\mathrm{X}$ ') are aggregated into a single value, in any time period, productivity can be viewed as either the ratio of the output value aggregate $\mathrm{Q}(\mathrm{Y})$ to the input value aggregate $\mathrm{Q}(\mathrm{X})$ (i.e., $T F P=Q(Y)$ / $Q(X)$ ), or the difference between the 2 quantities (i.e., $T F P=Q(Y)-Q(X))$. According to Diewert (2005), if the ratio measure of TFP is used (i.e. $Q(Y) / Q(X)$ ), the resulting measure is called an index, whereas if the second additive definition is used, the measure is called an indicator. In order to assess how productivity has changed between time periods, referred to as $t$ and 0 , productivity change is then either $T F P_{\mathrm{t}} / T F P_{0}$, or $T F P_{\mathrm{t}}$ $-T F P_{0}$.

There have been a large number of studies in which an index number is used to measure change in productivity in fisheries (Squires, 1992; Jin et al., 2002; Fox et al., 2003; Brandt, 2007; Stephen and Vieira, 2013; Walden and Kitts, 2014; Pan and Walden, 2015). The difference between these studies was usually in the way in which the index number was constructed, and in the prices used to weight the inputs and outputs. In recent reports by the U.S. and Australian governments, index numbers were used to track trends over different time periods for multiple fisheries (Stephen and Vieira, 2013; Walden et al., 2015). However, there have been no studies that we are aware of in which an indicator has been used to measure changes in productivity in a commercial fishery.

In this study, we introduce and measure change in productivity on the basis of differences with the Bennet-Bowley ( $\mathrm{BB}$ ) indicator. The $\mathrm{BB}$ indicator is an attractive method to measure productivity change because it can be easily constructed in spreadsheet software and it has additive properties that allow one to construct the indicator at the vessel level and then aggregate results to the overall fishery level. It does not require complex statistical or aggregation methods to measure a change in productivity. Our work contributes to fisheries productivity studies by showing how the $\mathrm{BB}$ indicator can be constructed to examine change in productivity, and how it can then be aggregated to the fleet or fishery level. Therefore, the BB indicator becomes another measure of productivity that can be added to the growing toolbox of techniques used to measure a change in productivity in commercial fisheries. We also show how a simple volume indicator can be constructed to measure changing biomass, which can then be combined with the productivity measure to arrive at a measurement of biomass-adjusted productivity. As far as we know, our study is the first that specifically uses the $\mathrm{BB}$ indicator to assess change in productivity in a commercial fishery.

The $\mathrm{BB}$ indicator is used to measure change in productivity in the northeast multispecies fishery (i.e., groundfish fishery) over a period covering the transition to catch share management. It is used to examine both the contribution of vessels entering, exiting, and continuing within the groundfish fishery to productivity change, and also the impact of changing species mix and quantities of inputs used on productivity. Results show a significant decline in productivity after conversion to catch shares-a decline caused by declines in output quantities, and an overall decline in productivity among "continuing" vessels. Because continuing vesssels composed the largest vessel group, they had the most influence over total change in productivity. Breakdown of the BB indicator into groups of outputs and inputs showed that declines in quantities of outputs overwhelmed declines quantities of inputs after the catch share system was incorporated. Although vessels were able to reduce their use of inputs somewhat, the influence of declining outputs was greater and resulted in negative productivity. Until there is further growth in outputs resulting from improved biomass, or consolidation of the fleet, increases in productivity are unlikely to occur.

\section{Materials and methods}

We are interested in measuring both the overall productivity change at the fishery level, and the contribution of different segments of a fishing fleet to a change 
in overall productivity. Specifically, we wish to examine how the productivity of vessels entering, exiting, and continuing within the fishery taken together influences the aggregate productivity measure. In order to accomplish both tasks, we use the BB indicator, which is a price-weighted arithmetic mean of the difference in the change in output quantities and input quantities used by firms (i.e., vessels) (Färe et al., 2008; Balk, 2010). First, we show how to derive the BB indicator, and then how it can be decomposed into 3 components: 1) the productivity of exiting vessels, 2) the productivity of entering vessels, and 3 ) the productivity of continuing vessels within the fishery. This decomposition will allow us to assess the contribution of each group to overall productivity. A similar approach was used to assess productivity gains in the mid-Atlantic individual transferable quota (ITQ) fishery for the Atlantic surfclam (Spisula solidissima) and ocean quahog (Arctica islandica) over a 30-year time period by using the Färe-Primont index (Färe et al., 2015). However, that approach required weighting individual productivity scores by input distance functions. The BB indicator differs because it requires no weighting of individual productivity measures, and it can be constructed in spreadsheets. Therefore, it is easier than the Färe-Primont approach for constructing the overall indicator. After examining the influence of entering and exiting vessels, we then extend the analysis in a different direction and use the additive nature of the $\mathrm{BB}$ indicator to determine how the composition of outputs produced and inputs used have influenced productivity change. The additive nature of the $\mathrm{BB}$ indicator allows us to see how landings mix and how changing input use have influenced productivity change.

In terms of notation, let $x^{1} \in \mathfrak{R}_{+}^{\mathrm{N}}$ be an input vector at time $\tau$ and let $y^{1} \in \mathfrak{R}_{+}^{\mathrm{M}}$ be an output vector, $t=t, t+1$. Let the corresponding prices be $w^{1} \in \mathfrak{R}_{+}^{\mathrm{N}}$ and $p^{1} \in \mathfrak{R}_{+}^{\mathrm{M}}$. The BB indicator takes the following form:

$$
\begin{aligned}
B B_{\mathrm{t}}^{\mathrm{t}+1} & =\frac{1}{2}\left[\frac{p^{\mathrm{t}}}{p^{\mathrm{t}} g_{\mathrm{y}}+w^{\mathrm{t}} g_{\mathrm{x}}}+\frac{p^{\mathrm{t}+1}}{p^{\mathrm{t}+1} g_{\mathrm{y}}+w^{\mathrm{t}+1} g_{\mathrm{x}}}\right]\left[y^{\mathrm{t}+1}-y^{\mathrm{t}}\right] \\
& -\frac{1}{2}\left[\frac{w^{\mathrm{t}}}{p^{\mathrm{t}} g_{\mathrm{y}}+w^{\mathrm{t}} g_{\mathrm{x}}}+\frac{w^{\mathrm{t}+1}}{p^{\mathrm{t}+1} g_{\mathrm{y}}+w^{\mathrm{t}+1} g_{\mathrm{x}}}\right]\left[x^{\mathrm{t}+1}-x^{\mathrm{t}}\right] \\
= & \frac{1}{2} \sum_{\mathrm{m}=1}^{\mathrm{M}}\left[\frac{p_{\mathrm{m}}^{\mathrm{t}}}{p^{\mathrm{t}} g_{\mathrm{y}}+w^{\mathrm{t}} g_{\mathrm{x}}}+\frac{p_{\mathrm{m}}^{\mathrm{t}+1}}{p^{\mathrm{t}+1} g_{\mathrm{y}}+w^{\mathrm{t}} g_{\mathrm{x}}}\right] \Delta y_{\mathrm{m}} \\
& -\frac{1}{2} \sum_{\mathrm{n}=1}^{\mathrm{N}}\left[\frac{w_{\mathrm{n}}^{\mathrm{t}}}{p^{\mathrm{t}} g_{\mathrm{y}}+w^{\mathrm{t}} g_{\mathrm{x}}}+\frac{w_{\mathrm{n}}^{\mathrm{t}+1}}{p^{\mathrm{t}+1} g_{\mathrm{y}}+w^{\mathrm{t}+1} g_{\mathrm{x}}}\right] \Delta x_{\mathrm{n}},
\end{aligned}
$$

which is a price-weighted difference between output change $y^{\mathrm{t}+} 1-y^{\mathrm{t}}$ and input change $x^{\mathrm{t}+} 1-x^{\mathrm{t}}$. The weights used, which are the terms in the square brackets are formed by using directional vectors $\left(g_{\mathrm{x}}, g_{\mathrm{y}}\right), g_{\mathrm{x}} \in \mathfrak{R}_{+}^{\mathrm{N}}$ and $g_{\mathrm{y}} \in \mathfrak{R}_{+}^{\mathrm{M}}$. Values need to be chosen for these vectors, and one possible choice is to set the directional vectors $\left(g_{\mathrm{x}}\right.$, $g_{y}$ ) equal to the observed input and output levels. Doing so makes the denominators in the bracketed term equal to the sum of total revenue and total cost. Instead, we set the value of the directional vectors equal to $(1,1)$, which restricts the sum of the weights found in Equation 1 to equal one, and is consistent with sharevalued weights.

Note that the weights include both outputs and input prices-a consequence of the fact that the indicator is derived from profit maximization. A useful property of the $\mathrm{BB}$ indicator is additivity, i.e., that the vessellevel $\mathrm{BB}$ indicators can be added together and it will be equivalent to the industry-level calculated BB indicator. We assume that each group and each unit member face the same prices which gives us our desired decomposition, namely the ability to group our fleet into 3 different sets of entering (N), continuing (C), and exiting (E) vessels, and the sum of the indicator for each group will equal the total indicator:

$$
B B_{\mathrm{t}}^{\mathrm{t}+1}=\left(B B^{\mathrm{C}}\right)_{\mathrm{t}}^{\mathrm{t}+1}+\left(B B^{\mathrm{N}}\right)_{\mathrm{t}}^{\mathrm{t}+1}+\left(B B^{\mathrm{E}}\right)_{\mathrm{t}}^{\mathrm{t}+1} .
$$

To illustrate how the decomposition works, for new units the indicator equals

$$
\begin{aligned}
\left(B B^{\mathrm{N}}\right)_{\mathrm{t}}^{\mathrm{t}+1} & =\frac{1}{2}\left[\frac{p^{\mathrm{t}}}{p^{\mathrm{t}} g_{\mathrm{y}}+w^{\mathrm{t}} g_{\mathrm{x}}}+\frac{p^{\mathrm{t}+1}}{p^{\mathrm{t}+1} g_{\mathrm{y}}+w^{\mathrm{t}+1} g_{\mathrm{x}}}\right]\left(\sum_{\mathrm{k}=1}^{\mathrm{K}} y_{\mathrm{k}}^{\mathrm{t}+1}\right) \\
& -\frac{1}{2}\left[\frac{w^{\mathrm{t}}}{p^{\mathrm{t}} g_{\mathrm{y}}+w^{\mathrm{t}} g_{\mathrm{x}}}+\frac{w^{\mathrm{t}+1}}{p^{\mathrm{t}+1} g_{\mathrm{y}}+w^{\mathrm{t}+1} g_{\mathrm{x}}}\right]\left(\sum_{\mathrm{k}=1}^{\mathrm{K}_{\mathrm{n}}} x_{\mathrm{k}}^{\mathrm{t}+1}\right) .
\end{aligned}
$$

Because these "new" units did not exist in period $t$, their inputs and outputs are zero at $t$. For the exiting units, inputs and outputs are zero in period $t+1$ and therefore the indicator equals

$$
\begin{aligned}
\left(B B^{\mathrm{E}}\right)_{\mathrm{t}}^{\mathrm{t}+1} & =\frac{1}{2}\left[\frac{p^{\mathrm{t}}}{p^{\mathrm{t}} g_{\mathrm{y}}+w^{\mathrm{t}} g_{\mathrm{x}}}+\frac{p^{\mathrm{t}+1}}{p^{\mathrm{t}+1} g_{\mathrm{y}}+w^{\mathrm{t}+1} g_{\mathrm{x}}}\right]\left(-\sum_{\mathrm{k}=1}^{\mathrm{K}_{\mathrm{E}}} y_{\mathrm{k}}^{\mathrm{t}}\right) \\
& -\frac{1}{2}\left[\frac{w^{\mathrm{t}}}{p^{\mathrm{t}} g_{\mathrm{y}}+w^{\mathrm{t}} g_{\mathrm{x}}}+\frac{w^{\mathrm{t}+1}}{p^{\mathrm{t}+1} g_{\mathrm{y}}+w^{\mathrm{t}+1} g_{\mathrm{x}}}\right]\left(-\sum_{\mathrm{k}=1}^{\mathrm{K}} x_{\mathrm{k}}^{\mathrm{t}}\right) .
\end{aligned}
$$

\section{Adjusting for a change in biomass with a volume indicator}

Fishing vessels produce landed fish that are extracted from a stock, and changes in productivity between 2 periods are linked to the changes in fish stocks. For example, if a fish stock declines between years, a fishing vessel may still be able to maintain the same level of landings as those of the prior year by increasing effort, which means a greater use of inputs. Consequently, a productivity indicator such as the BB indicator would decline between years because the quantity of outputs would stay the same, whereas the quantity of inputs would increase. The relationship between productivity change and biomass change has been recognized for some time now. Failing to account for a change in biomass results in a measure of productivity that has been called "biased" in the past (Squires, 1992). More recent studies have used the terms "biomass adjusted" and "biomass unadjusted" productivity change (Walden 
et al., 2015). What is usually important to managers and others is how policy changes have impacted productivity separately from changes in biomass, which is why a biomass-adjusted measure is desired.

Because we wish to isolate the change in productivity that is associated with changing outputs and inputs from a productivity change associated with changing fish biomass, a method needs to be used to separate productivity change from the change in biomass in the overall productivity metric. We follow the approach used by Jin et al. (2002) and construct an indicator of change in biomass which is then subtracted from the overall $\mathrm{BB}$ indicator. In this way, we are treating biomass as an input, recognizing that biomass is then transformed into an output by the fishing vessel. However, the biomass measure is subtracted from the overall $\mathrm{BB}$ indicator, rather than at the individual vessel level. From a social planner's perspective, biomass that is not harvested by the fleet during the current production period, has the potential to be transformed into an output in the next period. In our paradigm, the biomass is not under control of the vessel, and improvements in biomass in subsequent periods do not directly translate into increased future harvests because managers set the total allowable catch for each period.

The biomass indicator we choose has been developed previously and is called a "volume indicator" (VI) (Moosberg et al. ${ }^{1}$ ). The VI is calculated as follows:

$$
\begin{aligned}
V I & =\frac{1}{2}\left(p^{\mathrm{t}+1}+p^{t}\right)\left(s^{\mathrm{t}+1}-s^{t}\right) \\
& =\frac{1}{2}\left(\sum_{\mathrm{b}=1}^{\mathrm{B}} p_{\mathrm{b}}^{\mathrm{t}+1} s_{\mathrm{b}}^{\mathrm{t}+1}-p_{\mathrm{b}}^{\mathrm{t}+1} s_{\mathrm{b}}^{\mathrm{t}}+p_{\mathrm{b}}^{\mathrm{t}} s_{\mathrm{b}}^{\mathrm{t}+1}-p_{\mathrm{b}}^{\mathrm{t}} s_{\mathrm{b}}^{\mathrm{t}}\right),
\end{aligned}
$$

where $s=$ the spawning stock biomass of species $b$ in period $t$ or $t+1$; and

$p=$ the price of species $b$ in period $t$ or $t+1$.

The VI is needed for multispecies fisheries so that all species in the multispecies complex can be included in a single composite indicator. However, the same formula can also be used for a single species fishery. After VI has been calculated, it is then subtracted from the unadjusted $\mathrm{BB}$ indicator to arrive at what we term a "biomass adjusted" indicator of productivity:

$$
B B_{\mathrm{BA}}^{\mathrm{t}}=B B_{\mathrm{BU}}^{\mathrm{t}}-V I^{\mathrm{t}}
$$

where subscript $B A=$ biomass adjusted; subscript $B U=$ biomass unadjusted; and

$$
t=\text { time period. }
$$

\section{The northeast multispecies fishery}

Before describing the data that are used in the BB indicator, a brief description of the fleet and fishery are

\footnotetext{
${ }^{1}$ Moosberg, H. J., R. Färe, S. Grosskopf, and P. Roos, 2007. Volume and price indicators: decomposition and revenue with an application to Swedish pharmacies, 8 p. Department of Economics. Oregon State Univ., Corvallis, Oregon.
}

in order. There are 13 fish species included in the fishery management plan for what is commonly referred to as the New England groundfish fishery; additional species are caught as bycatch and are not considered part of the fishery management plan. The species included in the New England groundfish fishery are the American plaice (Hippoglossoides platessoides), Atlantic cod (Gadus morhua), Atlantic halibut (Hippoglossus hippoglossus), pollock (Pollachius virens), Atlantic wolffish (Anarhichas lupus), haddock (Melanogrammus aeglefinus), ocean pout (Zoarces americanus), Acadian redfish (Sebastes fasciatus), white hake (Urophycis tenuis), windowpane (Scophthalmus aquosus), winter flounder (Pseudopleuronectes americanus), witch flounder (Glyptocephalus cynoglossus), and yellowtail flounder (Limanda ferruginea). Atlantic wolffish, ocean pout, and windowpane are currently prohibited from being landed. The fishing fleet operates between Cape Hatteras, North Carolina, and the U.S.-Canadian border. In fishing year 2013 (1 May 2013-30 April 2014), the total exvessel value of landings from groundfish species landed in the fishery was approximately $\$ 55.2$ million (U.S \$2010), although revenue from both groundfish and non-groundfish species landed on groundfish trips was approximately $\$ 270$ million. Revenue was estimated on the basis of 327 vessels that completed a designated groundfish trip.

In May 2010, Amendment 16 to the northest multispecies plan (available at website, accessed March 31 , 2017) was implemented, which expanded the use of catch shares within a voluntary sector system. Vessel owners were allocated a share of the total allowable catch (TAC) for 9 different groundfish species ${ }^{2}$ on the basis of their historical landings. ${ }^{3}$ However, vessel owners were only allowed to catch their quota if they operated within a harvest cooperative (i.e., approved fishing sector). The amount of each species that could be potentially harvested by a sector (allowable catch entitlement, or ACE) is the sum of individual shares that each vessel brings into the sector. Sector management then set the rules for managing their portfolio of species for the benefit of sector members. Vessel owners wishing to buy, lease, or sell their ACE are subject to the trading rules for their respective sector. These rules may specify that trades take place within the sector before transactions are made with owners in a different sector. Thus, the ACE is not as freely tradable as an ITQ. Additionally, vessels are still subject to year round area closure regulations, which were retained from the prior plan, but fishermen may request exemptions from seasonal closures and trip limits.

\footnotetext{
${ }^{2}$ Species included the Atlantic redfish, pollock, white hake, witch flounder,American plaice, winter flounder, yellowtail flounder, Atlantic cod, and haddock. Additionally, some species had TAC assigned by stock area. The qualifying period for determining each owner's TAC was 1996-2006.

${ }^{3}$ Under the prior Amendment 13, 2 small sectors had been allowed to form which both harvested Atlantic cod from Georges Bank. Amendment 16 substantially expanded the number of allowed sectors.
} 
Each sector must hold an ACE (which includes both landings and discards) for all species in an area where a vessel is to fish. Because different species are often caught together in a single area, stocks for which where there is a low overall quota have the potential to shut off fishing of more abundant stocks, and are referred to as "choke" stocks. Once an ACE is exhausted for a single species in a sector, no further fishing in the stock area can take place by sector members, thereby limiting fishing for other species for which sectors have an available ACE. Essentially, there is not enough available supply of ACE for these stocks to satisfy demand for an ACE within the sector. Depending on the trading rules for a given sector, members can go outside their own sector to lease additional ACE if it is available and needed.

Before Amendment 16, vessels did not operate under hard quotas for most stocks, but rather under target TACs, which were set for the fishery as a whole. Under a target TAC, fishing could continue even if the TAC was exceeded, and then additional fishing restrictions would be put in place the following fishing year to adjust the harvest to an appropriate level given the excess harvest. In some respects, the catch share system is more restrictive than the past controls of fishing effort, although sector members can request waivers from some of the individual regulations on fishing effort that still exist. We also note that the hard quotas imposed would still be part of any management system chosen. When sectors were proposed as a management option, there was a great deal of uncertainty about future quotas. Nevertheless, it was hoped that the sector system would help stabilize a fleet that had been in a state of decline for several years. There was a sense that the system would allow the fishing fleet to get away from the "regulatory treadmill" that had plagued it for years with continually changing regulations to control fishing effort (Lee and Thunberg, 2013).

During the first year of the plan, roughly $98 \%$ of the ACE was held by vessels that joined sectors (Lee and Thunberg, 2013). It should be noted that each sector acts independently to further the self-interest of its members. Generally, vessel owners within a sector have been treating the quota they bring into a sector as their own allocation, such as they would have done within an ITQ system. Each sector member is jointly liable with other sector members if the sector exceeds its allocation for any stock. A large amount of monitoring takes place within sectors to ensure that allocation for any species is not exceeded.

Vessel owners that elected not to join a sector are allowed to use their vessels under the "common pool" system, where they are subject to regulations on fishing effort, along with an aggregate allowable catch limit (ACL) for each species. Under this system, each vessel is allocated a number of fishing days for the entire fishing year, and vessels are allowed to lease, buy, or sell days with other members of the common pool. However, trading is highly restricted because vessels can trade only with other vessels of similar size. This restriction was meant to prevent days from being transferred from vessels with low fishing power to those with higher fishing power. Vessels under the common pool system are also subject to the same year round area closures as are vessels fishing in the catch share system; moreover they are subject to seasonal closures from which sector vessels may obtain an exemption. The ACL applies to all vessels in the common pool and could potentially lead to fishing derbies as vessels try to fish their days as quickly as possible before the fishery is shut down. Currently, the ACLs for the common pool are divided into 3 trimesters to smooth catch levels over the year.

There are several different types of fishing vessels that harvest species managed in the fishery, but we limit this study to vessels which used otter trawl, gillnet, or longline gear and landed catch on identified groundfish trips. These gear groups are used to harvest the majority of the landings in this fishery and are consistent with the methods used by others to assess productivity change in this fishery (Murphy et al., 2015). Otter trawl nets are towed behind a vessel to catch fish and are considered a mobile gear. Fixed panels of nets are used with gillnet vessels and baited hooks on set lines in the water column are used with longline vessels, and both types of vessels then retrieve the fishing gear after a certain amount of time. Both gears are considered fixed gear. Between 2007 and 2013, the number of vessels in these gear groups declined dramatically, from 585 to 283 (Table 1). On average, the size of the vessels (by tonnage and horsepower) increased over the same time period, whereas the average number of trips declined and average days at sea increased. During 2013 , the average number of trips was quite low (28.9), whereas the average days spent fishing increased to 55.2 , the highest level during the time period. Average revenue, which was based on all species caught on trips which were identified as a multispecies trips, peaked in 2011 at $\$ 298,400$ (U.S. $\$ 2010$, Table 1). After 2011, revenue declined for the following 2 years. After implementation of the catch share system, revenues earned were higher than the 3 years before implementation of the management plan (2007-2009).

\section{Data}

In order to derive the $\mathrm{BB}$ indicator, data on quantities landed, inputs used to produce the corresponding landings, prices paid for the landings, and prices paid for the inputs used in the production process are needed. Because of the large number of species landed by groundfish vessels, the groundfish speices were separated into 6 different groups. Additionally, monkfish (Lophius americanus) was included in one of the groupings and the barndoor skate (Dipturus laevis), rosetta skate (Leucoraja garmani), winter skate (Leucoraja ocellata), clearnose skate (Raja eglanteria), thorny skate (Amblyraja radiata), little skate (Leucoraja erinacea), and smooth skate (Malacoraja senta) were broken out into their own category. These species are caught as bycatch on groundfish trips. The species groupings 


\section{Table 1}

Number of vessels, mean physical characteristics, effort, and revenue for vessels used to derive the Bennet-Bowley productivity indicator in this study to measure productivity change before and after the implementation of a catch share system in 2010 for the northeast groundfish fishery.

\begin{tabular}{|c|c|c|c|c|c|c|c|}
\hline Year & Vessels & $\begin{array}{c}\text { Mean } \\
\text { weight } \\
\text { (metric tons) }\end{array}$ & $\begin{array}{c}\text { Mean } \\
\text { length } \\
\quad(\mathrm{m})\end{array}$ & $\begin{array}{c}\text { Mean } \\
\text { horsepower } \\
\text { (hp) }\end{array}$ & Trips & $\begin{array}{l}\text { Mean } \\
\text { number } \\
\text { of days } \\
\text { fished }\end{array}$ & $\begin{array}{c}\text { Mean } \\
\text { value } \\
(\$ 1000 \mathrm{~s} \\
\text { U.S. 2010) }\end{array}$ \\
\hline 2007 & 585 & 54 & 16.2 & 426 & 39.9 & 44.4 & 210.2 \\
\hline 2008 & 535 & 54 & 16.2 & 429 & 43 & 46.6 & 214.2 \\
\hline 2009 & 489 & 52 & 16.2 & 428 & 45.8 & 47 & 209.8 \\
\hline 2010 & 371 & 54 & 16.2 & 446 & 28 & 43 & 239.5 \\
\hline 2011 & 344 & 57 & 16.5 & 455 & 34.9 & 54.6 & 298.3 \\
\hline 2012 & 338 & 58 & 16.5 & 460 & 33 & 53.6 & 246.1 \\
\hline 2013 & 283 & 59 & 16.8 & 467 & 28.9 & 55.2 & 241.6 \\
\hline
\end{tabular}

were Atlantic cod, haddock, roundfish (pollock, white hake, and monkfish), flatfish (yellowtail flounder, witch flounder, winter flounder, American plaice), skates (barndoor, rosetta, winter, clearnose, thorny, little, and smooth skates), and an "other" category which was all other species.

Inputs included fuel, ice (for storing fish), bait (only on vessels using hook-and-line gear), crew services, and capital user cost. The quantity of fuel used on each trip was calculated from trip level regression models (Walden and Kitts, 2014). Fuel price (\$2010, GDP implicit price deflator) was an average yearly price calculated from fuel prices collected on trips with an observer present (i.e., sampling trips). Crew services were the product of crew size obtained from vessel logbooks multiplied by the corresponding days the vessel spent at sea. Because crew members in this fishery are usually compensated by sharing in the proceeds from the trip, there is no observed wage rate (i.e., price of labor) to use in the index. Instead, the average hourly earnings for construction workers obtained from the Bureau of Labor Statistics (Current Employment Statistics, website, accessed March 2015) was used as a proxy for hourly crew wages because crews need to be compensated at least as much as they be for labor in other industries (i.e., opportunity cost). Although the choice of opportunity cost data may seem arbitrary, past studies have used similar approaches although the choice of alternative occupations has varied. For example, Squires (1992) used the average hourly wage in the retail, transportation, and manufacturing sectors in his study of the Pacific coast trawl fishery. Skirtun and Vieira (2012) used the hourly wages of agricultural workers in Australia in their study of profit drivers in Australian fisheries. Given the wide geographic distribution of vessels in our study (Maine to Virginia), we consider the wage rate for construction workers to be an appropriate measure for wages. Hourly wages multiplied by 8 was considered the daily opportunity cost of crew labor. The daily cost of food per crew member, calculated from sampling trips, was then added to the daily wage rate to obtain a total daily cost per crew member per day at sea.

In past studies, fishing vessel performance was mearsured by using the concept of capital services to measure the flow of capital (Squires, 1992; Dupont et al., 2005). In this study, we need both a price for capital and a quantity of capital for each time period. To calculate the price of capital during each period, we adopt the "capital user cost" concept (Balk, 2011), which is a per unit (vessel) cost constructed from 3 components: 1) the opportunity cost of capital, which reflects the the price which must be paid to an owner of an asset to prevent the asset from being sold (Balk, 2011); 2 ) the value change of the asset, which reflects both depreciation and re-investment in the asset (for the vessels in this study, only depreciation will be considered, because investment value is generally not available); and 3) the specific taxes levied on the use of an asset, which are not relevant to the fishing vessels in this study. We note that this approach is essentially the same method outlined by Christensen and Jorgenson (1969). However, we are limited in our ability to carry out these calculations because of a lack of data on investment value and because vessel values likely changed after the switch to sector management.

The value of capital was set at $\$ 5053$ per meter of vessel length (Pan and Walden, 2015), and the interest rate used was the yield for BAA-rated bonds (Squires, 1992; Walden and Kitts, 2014) deflated to 2010 levels by using the GDP implicit price deflator. Depreciation was set at $6 \%$, which was based on rates established by the U.S. Bureau of Economic Analysis. The quantity of capital used is the the percentage of recorded fishing time a vessel has spent in the groundfish fishery. A vessel that operates $100 \%$ of the time in the fishery has a value of 1 . By making this adjustment, the entire capital user cost is not charged to the groundfish 


\begin{tabular}{|c|c|c|c|c|c|}
\hline \multicolumn{6}{|c|}{ Table 2} \\
\hline \multicolumn{6}{|c|}{$\begin{array}{l}\text { Bennet-Bowley }(\mathrm{BB}) \text { productivity indicators, biomass volume indicator, and bio- } \\
\text { mass-adjusted BB productivity indicator for the period } 2007-2013 \text {. The BB indica- } \\
\text { tor is based on } 2 \text { years of data; therefore, the values for the row labeled } 2008 \text {, for } \\
\text { example, are results for the time period } 2007-2008 \text {. }\end{array}$} \\
\hline Year & $\begin{array}{l}\text { Output } \\
\text { indicator }\end{array}$ & $\begin{array}{c}\text { Input } \\
\text { indicator }\end{array}$ & $\begin{array}{c}\mathrm{BB} \\
\text { indicator }^{1}\end{array}$ & $\begin{array}{l}\text { Biomass } \\
\text { indicator }\end{array}$ & $\begin{array}{l}\text { Biomass- } \\
\text { adjusted } \\
\text { BB indicatior }\end{array}$ \\
\hline 2008 & 0.30 & -0.07 & 0.37 & -0.07 & 0.44 \\
\hline 2009 & 0.11 & -0.06 & 0.17 & -0.21 & 0.38 \\
\hline 2010 & -0.94 & -0.16 & -0.79 & -0.27 & -0.52 \\
\hline 2011 & 0.09 & 0.08 & 0.01 & -0.06 & 0.07 \\
\hline 2012 & -0.79 & -0.04 & -0.75 & -0.36 & -0.39 \\
\hline 2013 & -0.25 & -0.07 & -0.18 & -0.09 & -0.09 \\
\hline
\end{tabular}

fishery if the vessel operated part of the year in other fisheries (Färe et al., 2015).

In addition to fuel, labor, and capital, the quantity of ice used per trip was also included as an input category. Vessels that used longline gear included one additional input category, which was bait. Total bait cost was obtained from observer data, but it was only an aggregate cost with no price or quantity data. In order to include the quantity of bait, an average cost per day at sea for bait was calculated from sea sampling trips. Bait cost was then multiplied by days spent at sea (as recorded in the vessel logbooks) to obtain the total cost of bait for each trip. In the bait price and quantity components, days at sea were used as the quantity input, and the cost per day at sea for bait was the price component.

\section{Results}

The constructed BB indicator is shown with its component parts, namely the output indicator and input indicator, in Table 2. These are all normalized values $(\$ 1000$ s) where the normalization factor was the 2007 value of the overall quota (TAC) for most of the groundfish species (Table 2). ${ }^{4}$ The 2007 TAC value was picked as a normalization factor so that both the $\mathrm{BB}$ indicator and the VI used to measure changes in biomass would be normalized by the same factor. The $\mathrm{BB}$ indicator is based on 2 years of data, consequently when interpreting the results in Table 2, the row labeled 2008 provides results for the time period 2007-2008. Unlike a ratio-based index number, the $\mathrm{BB}$ indicator can be

\footnotetext{
${ }^{4}$ The species and stock areas included in the TAC value were Georges Bank Atlantic cod, Gulf of Maine Atlantic cod, Gulf of Maine haddock, southern New England yellowtail flounder, Gulf of Maine yellowtail flounder, American plaice, witch flounder, Georges Bank winter flounder, southern New England/mid-Atlantic winter flounder, white hake, and pollock.
}

either positive, or negative, with positive values indicating productivity increase and negative productivity decline.

The biomass-adjusted BB indicator showed increases in both 2008 and 2009, before dropping sharply in 2010 , which was the first year of the new catch share system (Table 2$)^{5}$. The drop-off was expected because the management system adopted strict catch limits and accountability measures for all participants. It was also consistent with the trend seen in the previously published Lowe index that was calculated for the annual performance report for this fishery (Murphy et al, 2015). ${ }^{6}$ Although the Lowe index and BB indicator are not directly comparable, overall the trends were generally consistent with one another. Between 2011 and 2013, the biomass-adjusted BB indicator continued to decline.

\section{Entry and exit}

As the BB indicator has been constructed, vessels that exit the fishery and do not fish in a year will always contribute negatively to the overall indicator, whereas entering vessels will always contribute positively. Vessels continuing within the fishery may either contribute positively or negatively to the indicator. Results show that productivity changes in any year are primarily being driven by vessels continuing withing the fishery (Table 3). Only in 2011 did entering vessels contribute

\footnotetext{
5 The species included in the biomass indicator were Georges Bank Atlantic cod, Gulf of Maine Atlantic cod, Gulf of Maine haddock, southern New England yellowtail flounder, Gulf of Maine yellowtail flounder, American plaice, witch flounder, Georges Bank winter flounder, southern New England/midAtlantic winter flounder, white hake, and pollock.

${ }^{6}$ The productivity estimates in the annual groundfish report were based on a 2007 base year, and were converted to annual changes to be consistent with the Bennet-Bowley indicator method.
} 


\section{Table 3}

Bennet-Bowley productivity indicator values unadjusted for biomass change for continuing, entering, and exiting vessels for the period 2007-2013 in the northeast groundfish fishery. Note: 2010 was the year in which the catch share system was implemented for this fishery.

\begin{tabular}{|c|c|c|c|c|c|c|c|}
\hline \multirow[b]{2}{*}{ Year } & \multicolumn{2}{|c|}{ Entering vessels } & \multicolumn{2}{|c|}{ Continuing vessels } & \multicolumn{2}{|c|}{ Exiting vessels } & \multirow[b]{2}{*}{$\begin{array}{l}\text { Total value } \\
\text { of } \mathrm{BB} \text { indicator }\end{array}$} \\
\hline & Indicator & $\begin{array}{c}\text { No. of } \\
\text { vessels }\end{array}$ & Indicator & $\begin{array}{c}\text { No. of } \\
\text { vessels }\end{array}$ & Indicator & $\begin{array}{c}\text { No. of } \\
\text { vessels }\end{array}$ & \\
\hline 2008 & 0.06 & 51 & 0.39 & 484 & -0.08 & 101 & 0.37 \\
\hline 2009 & 0.03 & 49 & 0.21 & 440 & -0.07 & 95 & 0.17 \\
\hline 2010 & 0.04 & 36 & -0.47 & 335 & -0.36 & 154 & -0.79 \\
\hline 2011 & 0.10 & 52 & 0.04 & 292 & -0.13 & 79 & 0.01 \\
\hline 2012 & 0.07 & 52 & -0.75 & 286 & -0.08 & 58 & -0.75 \\
\hline 2013 & 0.02 & 27 & -0.10 & 256 & -0.09 & 82 & -0.18 \\
\hline
\end{tabular}

more to the indicator than vessels continuing within the fishery when both values were positive. However, the number of vessels in the group continuing within the fishery each year was far greater than the number of entering vessels, and the additive nature of the indicator means that they should be contributing more to the indicator unless entering vessels were much more productive than continuing vessels. Even if entering vessels are more productive, their low numbers mean that, in aggregate, they do not contribute as much to the metric of fleet productivity. The large contribution by continuing vessels in the aggregate measure is consistent with that of other studies, which show that continuing vessels were the largest group after a change to a catch share system and contributed the most to aggregate productivity change (Walden et al., 2012; Färe et al., 2015). A catch share system, whether it is a cooperative system or an ITQ system, creates a barrier to entry owing to limited quotas and the initial rules for allocation. Entering vessels may need to buy or lease a quota, and therefore be more productive to offset the quota cost.

There was a core group of vessels within the fleet in our study that was present in all 6 years. In order to determine whether the move to a catch share system changed the productivity of these vessels, a nonparametric Kruskal-Wallis test was used to compare their normalized BB indicators before and after catch shares were implemented on an individual vessel basis. Results from the Kruskal-Wallis test indicated that the distributions were not equal (chi-square: 94.9, $\mathrm{df}=1$ ), and examination of the $\mathrm{BB}$ indicator showed that the postcatch share, the median value of the $\mathrm{BB}$ indicator $(-0.003)$, was lower than the precatch share (0.002). This result was consistent with the results for the whole fleet, which showed productivity declines after the catch shares were implemented. It is also consistent with separate findings for this fishery, which showed declines in productivity after the catch share system was put in place (Murphy et al., 2015).

A final question regarding these core vessels-a question that existed throughout the entire study period-was whether there were persistent differences in performance between the vessels within this group. In order to examine this question, vessels were separated into quartiles depending on unadjusted productivity (i.e., without biomass considered) in 2008. Unadjusted productivity was used because the VI used to measure a change in biomass affected all vessels equally. In other words, it did not shift a vessel into a different quartile. Productivity for each group was then tracked for the remaining years in the study (Fig. 1). Tracking of vessel groups allowed us to see whether the vessesl with higher productivity contributed the most to the indicator throughout the remaining years.

Vessels that were in the top quartile (i.e., with a higher degree of productivity) during 2008 contributed positively to the overall productivity gain in both 2008 and 2009, and, as a group, contributed more than the other 3 quartiles combined. In 2010, this same group of vessels contributed the most to productivity decline. Interestingly, the bottom quartile group in 2008 was the only group that showed a positive productivity gain in 2010. In 2011, the top 2008 quartile contributed negatively to overall productivity gain, whereas the other 3 quartiles contributed positively. In 2012 the top 2008 quartile group contributed the most to productivity decline, although there was little difference among all 4 groups. In 2013, all 4 groups had a negative productivity gain, and the third quartile group contributed the most to productivity decline. Summarizing these findings in terms of the top 2008 vessels shows that productivity gains for these vessels before catch shares turned into productivity declines after the switch to the catch share system.

The reversal in economic status for the top quartile indicates that, before the implementation of catch shares, those vessels were successful within the framework of regulations controlling fishing effort that existed during that time period and perhaps aided by permission to lease fishing days and the lack of hard 


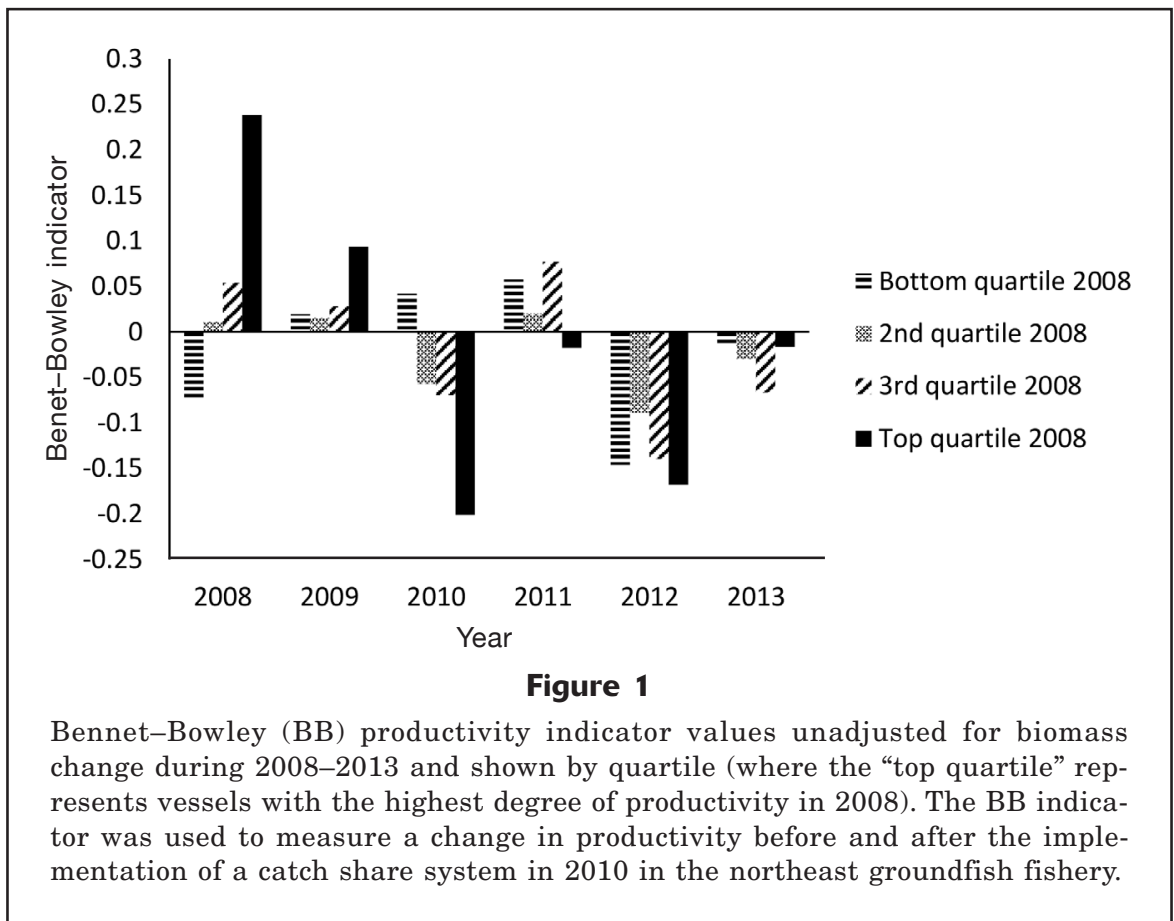

quotas on several species. During the catch share era (2010-2013), negative productivity gains occurred for these vessels in all 4 years. Unlike procedures of the precatch share era (2008-2009), the inability to continue fishing because of concerns about the proportion of bycatch in relation to target species in catches, and a lack of ACE for key species, may be hindering the ability of fishing crews to post productivity gains. Over time, these vessels may again be leaders in productivity gain, but it may take time for new trading arrangements and other institutional changes to allow these gains to occur.

\section{Changes in outputs and inputs}

Vessels could also improve their productivity by changing their input use, or switching their output targets, and harvesting a different mix of species. The output and input portions of the $\mathrm{BB}$ indicator can be examined separately, and doing so showed that, in both 2008 and 2009 before catch shares were implemented, the output indicator increased, whereas the input indicator decreased (Table 2). The years 2008 and 2009 were years before catch shares were implemented, and all vessels were under an input control system. The ability to reduce input use and increase outputs led to productivity gains during that time period. In the first year of the new management regine (2010), both the output and input indicators decreased. In the following year, 2011, the input indicator increased, and this year was the only one in the time series when this increase occurred. This gain is consistent with gain in the data seen in Table 1 , where both days at sea and the number of trips increased in 2011, along with an increase in the average size of vessels operating in the fishery. Generally, in years where both the output indicator and input indicator declined, the declining use of inputs was not enough to offset the declining outputs, and productivity declined.

One possible reason for the continuing decline in the output indicator could be deterioration of the fish stock biomass. Because the biomass indicator developed above is an additive measure, it can be used to both adjust the productivity metric and to examine trends in the species-specific components of overall biomass. A negative value in the biomass indicator indicates reduced fish biomass. Between 2008 and 2013, the biomass indicator was negative in all years (Table 2 ). The year 2010, which was the first year of the catch share plan, showed a particularly large drop in the VI $(-0.27)$.

Although the biomass indicator is used to adjust the $\mathrm{BB}$ indicator, it does not give a complete picture of how biomass is impacting vessel output. Specifically, if there are species interactions among the various stocks where they are caught jointly, the most constraining stock would likely be limiting catches of other stocks. Availability of species may also change if there is a spatial shift in the distribution of species. For example, species may shift more offshore to deeper colder water because of environmental changes. With a catch share system where quotas can be "unbundled" and leased on a species basis, it may be possible for quotas to be traded in a manner such that vessels that are specialists in one species can lease or buy quota that will not constrain their activities. The trading arrangements which would facilitate "unbundling" of quotas, however, may take some time to evolve. 
There is also a question of how the use of inputs changes after the transition to catch shares is implemented. Again, the additive property of the indicator shows how vessels altered their use of inputs after the transition to the new catch share plan (Table 2). With the exception of 2011, the total amount of inputs used by the fleet declined. The largest decline in the use of inputs occurred in 2010, the first year of the catch share plan. This drop in inputs was expected because the catch share plan gave vessels the opportunity to use their inputs differently as their output mix changed, or to exit the fishery. In an output-constrained fishery, reducing the use of inputs and the cost of fishing leads to increasing profitability (Squires et al., 2016).

\section{Discussion}

The BB indicator is a powerful tool that can be used to assess productivity change in commercial fisheries. The additive nature of the indicator allows it to be used for examining productivity change starting at the individual vessel level and then aggregating the individual results to the fleet or fishery level. Individual vessels can be grouped into different categories for comparison, such as entering, continuing, and exiting vessels, and it is possible to determine which groups are contributing the most to productivity change. Moreover, grouping vessels into different fleet segments can give managers additional insight into changes that have occurred in response to regulatory actions.

We applied the BB indicator to measure productivity change in the northeast multispecies fishery and found that productivity declined after catch shares were implemented because outputs declined more than inputs declined. There are a number of plausible reasons why outputs declined so much, but it is likely to have occurred because of lower quotas for key stocks. Because catches usually include a mixture of species, lower quotas for key species would constrain the catch of other more abundant species. These key species are usually referred to as "choke" species.

The BB indicator was used to examine the contribution of entering, continuing, and exiting vessels to productivity change. Results showed that continuing vessels contributed the most to productivity change each year because they were the largest fleet segment. This specific catch share system allows incumbent vessels some degree of protection from new entrants with no catch history because incumbent vessels are guaranteed a portion of the overall quota for each species for which they have catch history. As long as they can fish that quota profitably, they need not exit the fishery. The lack of improved productivity is similar to findings from studies of 2 other fisheries after implementation of ITQ systems in other parts of the world. In the first, gains in economic efficiency in a Norwegian purse-seine fishery did not occur after transition to an ITQ, and this outcome was attributed partially to the grandfathering of fishing rights (Nøstbakken, 2012). In a different study, after an ITQ system was implemented for the Peruvian anchovy fishery, productivity gains did not occur, but price increases did occur (Natividad, 2015). Over time, there may be productivity gains both in these 2 fisheries and the fishery we highlighted, but such gains are still uncertain. Although we expect less productive vessels to exit over time, externalities still exist that work against productivity gains. For example, vessels can still be displaced spatially by other vessels. If this displacement occurs, some crews (i.e., vessels) may have to use more inputs to reach new fishing areas, and overall vessel productivity may decline depending on how all the vessels adjust their fishing patterns.

An important part of any exercise that examines productivity trends for fisheries is adjustment for biomass change. Managers wish to know the impact of their policies on productivity of the fleet separately from any changes caused by differences in biomass. A volume indicator was constructed, which is similar to the $\mathrm{BB}$ indicator, to adjust for biomass in the fishery. The value of the volume indicator was subtracted from the $\mathrm{BB}$ indicator to arrive at a biomass-adjusted BB indicator. Declining biomass leads to a negative volume indicator, and subtracting this value means the adjusted $\mathrm{BB}$ indicator will be greater than the unadjusted $\mathrm{BB}$ indicator. In other words, productivity apart from biomass would increase. In this study, the biomass adjustment did not change the sign of the $\mathrm{BB}$ indicator, but it did change the magnitude. Negative productivity changes were still negative, but not as negative as the unadjusted productivity indicator. The issue of adjusting the productivity metric by biomass change is important, and further research needs to be conducted on making adjustments at the vessel level to account for biomass change. Because the fleet $\mathrm{BB}$ indicator is an aggregate value, subtracting the biomass indicator is an acceptable approach.

Productivity change is an important economic metric for managers to track when gauging economic performance, and the BB indicator is a very easy to construct and flexible measure. However, productivity change is just one metric and needs to be combined with other metrics, such as price changes, profitability, and fleet size to give meaningful signals to managers. The northeast groundfish fishery is still in a transition phase in terms of vessels fully adjusting to the catch share system, and productivity gains may not be seen for several years, particularly if stock conditions do not improve. However, productivity change in a fishery will be limited because the vessels are harvesting a finite resource, and in any year total output is capped by the allowable harvest. Fishery regulations are designed to limit output, and productivity gains will eventually peak even with full transferability of quota. Ultimately, managers may want to move toward a measure of profitability, rather than productivity, if there are enough cost data available to gauge economic performance. Profitability would give a better indication of the health of the fishing fleet than productivity by itself. 


\section{Acknowledgments}

We thank E. Thunberg, M. Simpkins, and 2 anonymous reviewers for helpful comments and suggestions. This research was funded by the Office of Science and Technology, National Marine Fisheries Service. The views in this article are the authors alone and do not represent those of Oregon State University.

\section{Literature cited}

Balk, B. M.

2010. An assumption-free framework for measuring productivity channge. Rev. incone wealth 56:S224-S256. Article

2011. Measuring and decomposing capital input cost. Rev. Income Wealth 57:490-512. Article

Brandt, S.

2007. Evaluating tradable property rights for natural resources: the role of strategic entry and exit. J. Econ. Behav. Organ. 63:158-176. Article

Christensen, L. R., and D. W. Jorgenson.

1969. The measurement of U.S. real capital input, 19291967. Rev. Income Wealth 15:293-320.

Clay, P. M., A. Kittts, and P. Pinto da Silva.

2014. Measuring the social and economic performance of catch share programs: definition of metrics and application to the U.S. Northeast Region groundfish fishery. Mar. Policy 44:27-36. Article

Diewert, W. E.

2005. Index number theory using differences rather than ratios. Am. J. Econ. Sociol. 64:311-360.

Dupont, D. P., K. J. Fox, D. V. Gordon, and R. Q. Grafton.

2005. Profit and price effects of multi-species individual transferable quotas. J. Agric. Econ. 56:31-57. Article

Färe, R., S. Grosskopf, and D. Margaritis.

2008. Efficiency and productivity: Malmquist and more. In The measurement of productive efficiency and productivity growth (H. O. Fried, C. A. K. Lovell, and S. S. Schmidt, eds.) p. 522-621. Oxford Univ. Press, New York.

Färe, R., S. Grosskopf, and J. Walden.

2015. Productivity change and fleet restructuring after transition to individual transferable quota management. Mar. Policy 62:318-325. Article

Fox, K. J., R. Q. Grafton, J. Kirkley, and D. Squires.

2003. Property rights in a fishery: regulatory change and firm performance. J. Environ. Econ. Manage. 46: 156-177. Article

Jin, D., E. Thunberg, H. Kite-Powell, and K. Blake.

2002. Total factor productivity change in the New England groundfish fishery: 1964-1993. J. Environ. Econ. Manage. 44:540-556. Article

Lee, M.-Y. A., and E. M. Thunberg. 2013. An inverse demand system for New England ground- fish: welfare analysis of the transition to catch share management. Am. J. Agric. Econ. 95:1178-1195. Article

Murphy, T., A. Kitts, C. Demarest, and J. Walden.

2015. 2013 final report on the performance of the northeast multispecies (groundfish) fishery (May 2013-April 2014). U.S. Dep. Commerce, Northeast Fish. Sci. Cent. Ref. Doc. 15-02, 106 p. Document

Natividad, G.

2015. Quotas, productivity, and prices: the case of anchovy fishing. J. Econ. Manage. Strategy 25:220-257.

Nøstbakken, L.

2012. Investment drivers in a fishery with tradable quotas. Land Econ. 88:400-424. Article

Pan, M., and J. Walden.

2015. Measuring productivity in a shared stock fishery: a case study of the Hawaii longline fishery. Mar. Policy 62:302-308. Article

Skirtun, M., and S. Vieira.

2012. Understanding the drivers of profitability in Commonwealth fisheries electronic resource. ABARES Tech. Rep. 12.4, 46 p. Aust. Bur. Agric. Res. Econ. Sci., Canberra, Australia.

Squires, D.

1992. Productivity measurement in common property resource industries: an application to the Pacific coast trawl fishery. RAND J. Econ. 23:221-236.

Squires, D., M. Maunder, N. Vestergaard, V. Restrepo, R. Metzner, S. Herrick Jr., I. del Valle, and P. Andersen.

2016. Effort rights in fisheries management: General principles and case studies from around the world. In Effort rights in fisheries management: general principles and case studies from around the world; Bilbao, Spain, 17-20 September 2012 (D. Squires, M. Maunder, N. Vestergaard, V. Restrepo, R. Metzner, S. Herrick Jr., R. Hannesson, I. del Valle, and P. Andersen, eds.), p. 1-9. FAO Fish. Aquac. Proc. 34. FAO, Rome.

Stephan, M., and S. Vieira.

2013. Productivity analysis of key Commonwealth fisheries. ABARES Tech. Rep. 13.09, 44 p. Aust. Bur. Agric. Res. Econ. Sci., Canberra, Australia. [Available from website.]

Thunberg, E., J. Walden, J. Agar, R. Felthoven, A. Harley, S. Kasperski, J. Lee, T. Lee, A. Mamula, J. Stephen, and A. Strelcheck.

2015. Measuring changes in multi-factor productivity in U.S. catch share fisheries. Mar. Policy 62:294-301. Article

Walden, J. B., and N. Kitts.

2014. Measuring fishery profitability: an index number approach. Mar. Policy 43:321-326. Article

Walden, J. B., J. E. Kirkley, R. Färe, and P. Logan.

2012. Productivity change under an individual transferable quota management system. Am. J. Agric. Econ. 94:913-928. Article

Walden, J., B. Fissel, D. Squires, and N. Vestergaard.

2015. Productivity change in commercial fisheries: an introduction to the special issue. Mar. Policy 62:289-293. Article 